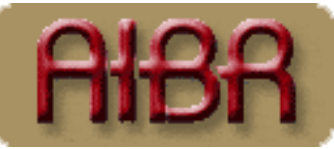

REVISTA DE ANTROPOLOGÍA IBEROAMERICANA

ESTIMADO LECTOR/A:

GRACIAS POR DESCARGAR ESTE ARTÍCULO. EL TEXTO QUE ESTÁ A PUNTO DE CONSULTAR ES DE ACCESO LIBRE Y GRATUITO GRACIAS AL TRABAJO Y LA COLABORACIÓN DESINTERESADA DE UN AMPLIO COLECTIVO DE PROFESIONALES.

USTED PUEDE AYUDARNOS A INCREMENTAR LA CALIDAD Y A MANTENER LA LIBRE DIFUSIÓN DE LOS CONTENIDOS DE ESTA REVISTA A TRAVÉS DE SU INSCRIPCIÓN A LA ASOCIACIÓN AIBR:

http://www.aibr.org/antropologia/aibr/socios.php

La asociación a AIBR tiene un coste mínimo al año, y le proporcionará las siguientes ventajas y privilegios:

1. Recibir en su domicilio la revista impresa, en Europa y América (tres números anuales), así como todas las novedades relativas al funcionamiento de la asociación.

2. Recibir en su domicilio, a precio especial o de forma gratuita, cuantas publicaciones adicionales edite la asociación.

3. Derecho a voto en las asambleas de socios, así como a presentarse como candidato a la elección de su Junta Directiva.

4. Recibir el boletín de socios (tres números anuales), así como la información económica relativa a cuentas anuales de la asociación.

5. Beneficiarse de las reducciones de precio en congresos, cursos, libros y todos aquellos convenios a los que a nivel corporativo AIBR llegue con otras entidades. En este momento, existen los siguientes acuerdos:

o Reducción de un $20 \%$ en el precio de todos los libros publicados por la editorial MELUSINA.

o Reducción de un $20 \%$ en el precio de todos los libros publicados por la editorial SEPHA.

o Reducción de un 30\% en el precio de todos los libros publicados por la editorial GRAN VÍA.

o Derecho a cuota reducida en los congresos trianuales de la FAAEE (España) y a los bianuales de la Sociedad Española de Antropología Aplicada.

o Derecho a cuota reducida en los congresos la IUAES.

6. Promoción gratuita, tanto a través de la revista electrónica como de la revista impresa, de aquellas publicaciones de las que sea autor y que estén registradas con ISBN. La difusión se realiza entre más de 5.000 antropólogos suscritos a la revista.

7. Cuenta de correo electrónico ilimitada de la forma socio@aibr.org, para consultar a través de webmail o cualquier programa externo.

8. Espacio para web personal de la forma http://www.aibr.org/(directorio)/(nombre) y cuenta propia de ftp.

9. Acceso con clave a todos los documentos de la Intranet de socios de AIBR, incluida la consulta a artículos en proceso de evaluación de la revista AIBR.

10. Promoción gratuita a través de la revista (banner rotativo y reseña) de aquellos eventos, congresos, conferencias o cursos en los que usted forme parte del comité organizador.

11. Opción a formar parte como evaluador de los artículos recibidos por la revista.

IMPORTE DE LA CUOTA ANUAL: Hasta diciembre de 2008, la cuota única anual es de 32 (euros). Su validez es de un año a partir del pago de la cuota. Por favor, revise la actualización de cuotas en nuestra web. 


\title{
Ais parentesco y Relaciones de género www.aibr.org EN UNA LOCALIDAD WIXARIKA (HUICHOL) DEL SUR DE DURANGO ${ }^{1}$
}

\section{Francisco Guízar Vázquez}

Profesor de Tiempo Completo, Centro de Investigación en Ciencias Agropecuarias, Universidad Autónoma del Estado de México, Dirección: Ignacio López Rayón Sur \#510, Col. Cuauhtémoc, CP 50130, Toluca, Estado de México. E-mail: fguizarv@gmail.com . Tlfno: (+52) (722) 2965552.

\begin{abstract}
Resumen
El objetivo del presente trabajo es contribuir al debate sobre el respeto a los derechos de los pueblos indígenas. Mediante un estudio de caso se ofrecen algunas reflexiones sobre temas que atañen a las relaciones de género y de parentesco, y sus implicaciones con la noción de respeto a los usos y costumbres. Se resalta el relevante papel del trabajo etnográfico, que aplicado desde una perspectiva analítica procesal, puede coadyuvar al estudio y conocimiento a profundidad de temas polémicos como la defensa de los derechos de las mujeres indígenas en los ámbitos familiares. Por lo tanto se adopta una propuesta que tome en cuenta el punto de vista del marginado, al mismo tiempo que contemple una visión no estática de los valores y cultura indígenas.
\end{abstract}

\section{Palabras clave}

Género, parentesco, wixarika, derechos de los pueblos indígenas

\begin{abstract}
The objective of this work is to contribute on the debate about the respect of indigenous rights. Based on a case study, it offers some reflections about certain concepts concerning gender and kinship relations, and their implications on the respect of the local customs. It stresses the important role played by the ethnographic work: If it is applied from a procedural analytical perspective, it may contribute to a deeper study of controversial topics, such as the defense of the indigenous women rights in domestic spaces. Therefore the position takes into account the point of view of those who are excluded, and also assumes a non-static vision about indigenous values and culture.
\end{abstract}

\section{Key words}

Gender, kinship, wixarika, indigenous peoples rights

\footnotetext{
${ }^{1}$ Este trabajo presenta parte de los resultados de mi proyecto de tesis de Doctorado, cuyo texto será publicado próximamente por la editorial de El Colegio de Michoacán. Este artículo se nutre de la colaboración y labor de sensibilización sobre el punto de vista de Género de la antropóloga Lorena Bayardo Platas.
} 


\section{Introducción}

$\mathrm{L}$

os derechos de las mujeres indígenas son un tema pendiente en la agenda de los gobiernos del actual Estado Mexicano. Las referencias en torno a los mismos en los discursos oficiales y de los movimientos indígenas comúnmente omiten aspectos que pueden resultar controversiales, como los de la violencia doméstica y la situación de desventaja que padecen las mujeres indígenas en el seno de sus comunidades. Aunque ya se ven movimientos de mujeres indígenas que sí abordan dichos factores (Hernández, 2001, 2003; Sierra, 1997), con la finalidad de aportar algunas propuestas de análisis que puedan enriquecer el debate, reflexiono sobre un estudio de caso sobre una singular localidad wixarika: Bancos de San Hipólito, situada al sur de Durango.

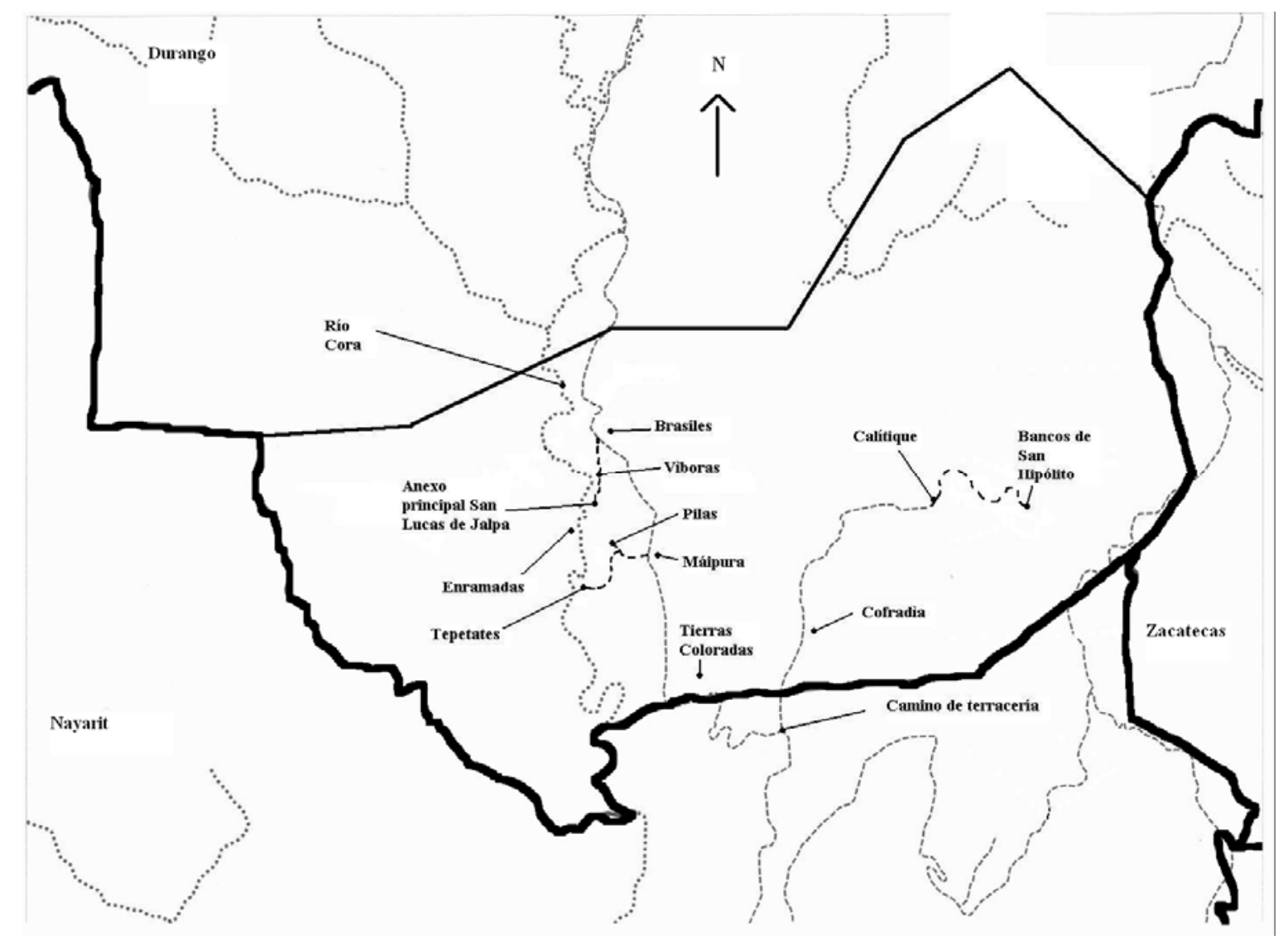

IMAGEN 1. Comunidad de San Lucas de Jalpa 
Desde los años sesenta del siglo pasado, esta ranchería indígena ha mantenido un conflicto agrario en contra de vecinos rancheros mestizos, quienes han logrado ocupar los mejores suelos agropecuarios y forestales, relegando a los indígenas a laborar las tierras magras de laderas y precipicios. Su larga lucha ha trascendido distintas coyunturas nacionales. En los últimos años, bajo el influjo político neoindigenista de los neo-zapatistas, se han proclamado comunidad autónoma o caracol. Las tensiones locales han mostrado un tinte eminentemente identitario y clasista, teñido por episodios recurrentes de violencia. En este contexto, resulta interesante resaltar algunos aspectos relevantes sobre las relaciones de poder entre los géneros.

Los cambios histórico-contextuales que sufre la organización étnica son un referente ineludible en el debate en torno a los principios que finquen la construcción del derecho relacionado con pueblos indígenas, pues constituyen un punto de tensión argumental entre las nociones estáticas y las dinámicas de lo jurídico. Para darle continuidad a la idea procesual de los fenómenos étnicos, me apoyo en la propuesta metódica de Nagel y Smith (1993) sobre la reorganización étnica, la cual se puede observar a través de diferentes ámbitos analíticos, como lo pueden ser la reorganización de las normas reguladoras de la membresía grupal, la de los límites étnicos, la del ámbito económico, la del ámbito social, etcétera.

En este sentido, analizaré la forma en que la creación y / o la transformación de campos sociales y el crecimiento demográfico sobre un espacio delimitado por fronteras identitarias han influido sobre la forma general de organización étnica de los wixaritari en sus aspectos de relaciones de género en torno al matrimonio y a la división del trabajo. Esta creación y/o transformación de esferas sociales implican el apuntalamiento estructural de nuevas formas de intercambio de capitales y de nuevas categorías intra e intergrupales. Concibo aquí la noción de campo social como la propone Bourdieu (1992: 71-72), constituida por un espacio social específico, en el que las relaciones entre los agentes se definen de acuerdo a la detentación de un capital relativo. Éstos, para obtener ventajas, compiten por posicionarse en una estructura diseñada bajo las normas más o menos específicas de un juego de poder. Los diferentes campos que se han consolidado en la organización étnica wixarika han sido resultado de las improntas de adaptación de sus agentes ante las presiones representadas por la hostilidad de sus 
vecinos mestizos y las oportunidades y limitantes estructurales que la sociedad en su conjunto ha construido en un esquema de relaciones nacional y global.

La investigación etnográfica la llevé a cabo de julio a septiembre de 2001, y de septiembre de 2002, a julio de 2003. Realicé alrededor de cincuenta entrevistas semiestructuradas, complementadas de observación participante y análisis de documentos de registros civiles y eclesiásticos. La investigación tenía como objetivo el analizar el conflicto intergrupal por los recursos naturales, sin embargo recabé información complementaria para sustentar un trabajo de etnografía fina.

\section{La vivienda como escenario}

La IMAGEN 2 representa grosso modo la actual jerarquía social de la comunidad agraria $^{2}$ de San Lucas de Jalpa donde se encuentra Bancos. Pueden variar relativamente las posiciones para casos aislados, pero en términos estructurales resulta relevante, pues representa una visión analítica de las relaciones intergrupales e intragrupales. Sin embargo genera una "tensión" cognoscitiva entre lo etic y lo emic: cada grupo étnico se percibe de una forma distinta con respecto a cada cual. De esta forma, y asumiendo una postura indagatoria, ofrezco una visión centrada en el plano de la interacción, donde las visiones de cualquier bando por necesidad son parciales. Es evidente que la estructura de las relaciones de género al interior del grupo étnico wixarika no se puede comprender aislándola de su relación intergrupal con los mestizos. El sentido histórico que los wixaritari han adjudicado a su interacción con los mestizos, ha influido en gran medida en la forma en que han estructurado sus relaciones de género, sus lazos de parentesco y sus reglas de residencia. Sin embargo me concentraré en este ensayo sobre las formas intragrupales de las relaciones de género y parentesco, señalando a grandes rasgos los factores intergrupales que influyen en las mismas.

\footnotetext{
${ }^{2}$ Por comunidad agraria, se entiende aquí al núcleo agropecuario definido en la Ley Agraria de México, y que corresponde a una forma de tenencia comunal de la tierra, donde la Nación es la propietaria de la misma. Sin embargo, desde 1992 se han impulsado múltiples reformas para facilitar el cambio de régimen de tenencia de las tierras comunales y ejidales.
} 


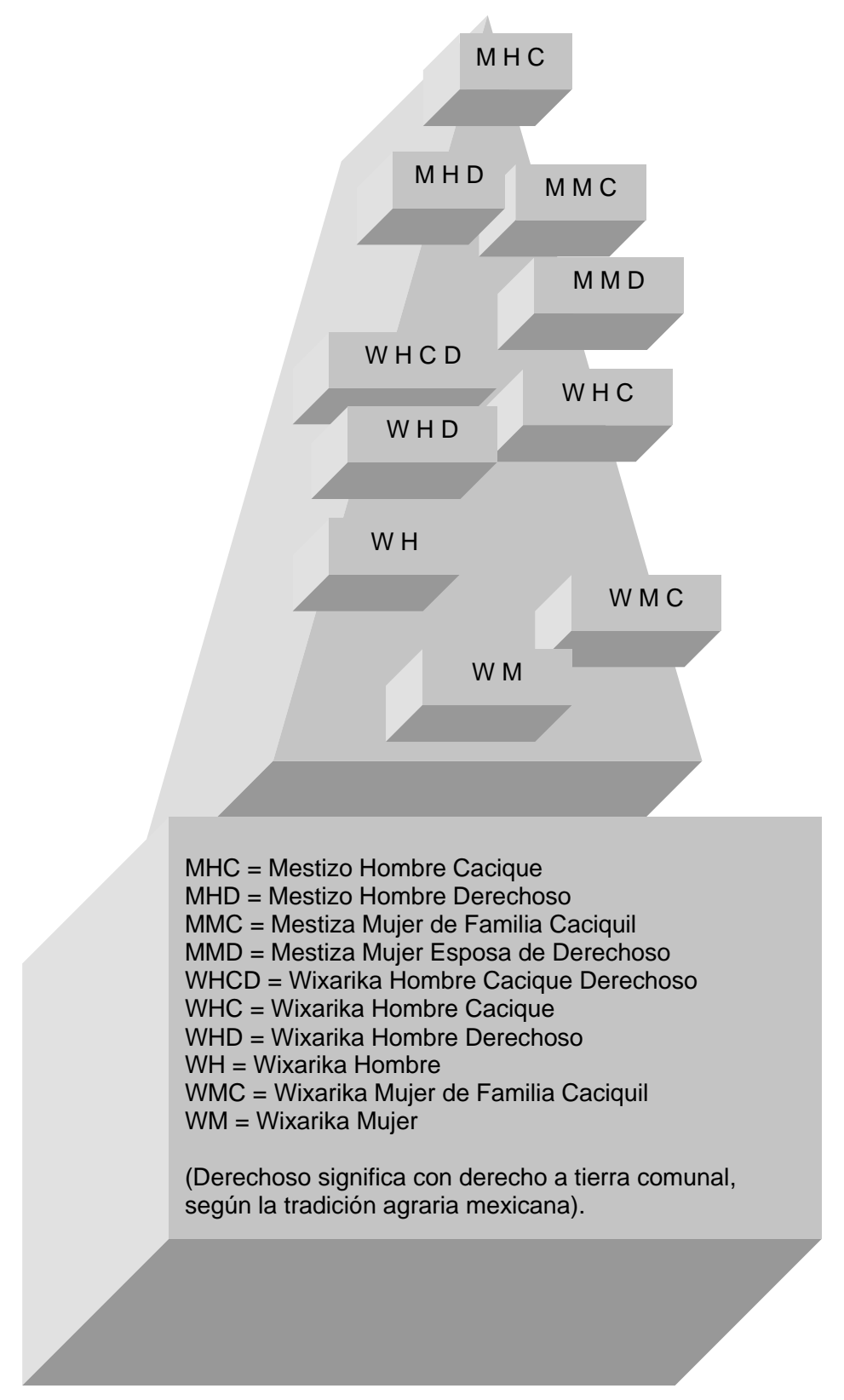

IMAGEN 2. Jerarquía social en San Lucas de Jalpa, El Mezquital, Durango, México.

En el presente trabajo se asume una posición no biológica del Género, en el sentido de que las relaciones vinculadas a su concepción responden más a nociones construidas socialmente, que a determinantes biológicos de la sexualidad en sentido laxo (González y Vizcarra, 2006: 27-28). Asimismo interesa analizar algunas prácticas sexuales por medio de las cuales se manifiestan las relaciones de género en un ambiente local, donde la cima jerárquica local es ocupada por un grupo de caciques 
mestizos. Las clases sociales son relevantes para manifestar la jerarquía local en ambos grupos. Por ejemplo, a pesar de consistir en un esquema patriarcal, el estatus social de esposa de cacique puede equiparar relativamente a una mujer con un mestizo pobre. El estigma intergrupal juega un papel importante al segmentar diagonalmente la distinción clasista, pues un wixarika, según la estructura temporal vigente, siempre padecerá de un estatus inferior con relación a un mestizo, a pesar de que el primero en ocasiones detente mayor capital económico.

Esta pirámide se cristaliza en las interacciones cotidianas y en el hecho tajante de la segregación territorial. Las relaciones de género son mejor observadas a un nivel doméstico, en los hogares. El escenario de la vivienda wixarika es un lugar donde se pueden contemplar las relaciones de poder que atañen directamente a los agentes que ocupan la base de la pirámide jerárquica, las cuales implican la interacción de agentes adscritos a categorías de grupo, de género, de clase y de edad, donde las mujeres ocupan la posición más baja de la misma. También se observan las tensiones ocasionadas por la consolidación y traslapamiento de nuevos campos o sub-campos que se han ido construyendo en los últimos años, como el de la política educativa y la artesanía, así como por las transformaciones que coyunturalmente se han suscitado en la organización social y en la composición demográfica de grupo.

Las casas llenan un terreno que en promedio mide unos treinta por treinta metros, donde los cuartos-dormitorio ocupan la parte periférica. Al centro hay un patio en el que se crían los animales domésticos (burros, mulas, cerdos, aves y perros) y se siembran hortalizas, plantas medicinales y hikuri" ("peyote" o Lophophora Williamsii). La cocina suele encontrarse en posición opuesta a los dormitorios. Como en el resto del territorio wixarika, todas las casas tienen una kareta (carretón), que es una construcción de madera, con techo de zacate a dos aguas, donde una plataforma de carrizos que sirve de piso ocupa una posición elevada, la cual mide desde el suelo hasta su base, entre un metro y un metro y medio de altura. Se utiliza para almacenar granos y utensilios, aunque también sirve como dormitorio, pues ofrece una alternativa más

\footnotetext{
${ }^{3}$ El hikuri es recolectado en la zona ecológica semi-desértica llamada Wirikuta, ubicada al noroeste del actual estado de San Luis Potosí, en México. Dicha planta es trasladada en canastos, para consumirla, o sembrarla con fines de conservación para su ulterior ingesta en los patios de las casas, sobre pequeños huertos diseñados especialmente para la misma.
} 
fresca para las cálidas noches de la mayor parte del año en la localidad. Cada vivienda en lo particular es ocupada normalmente a una familia nuclear (abuelos, hijos, nueras, yernos y nietos); un conjunto de casas agrupadas por manzana, generalmente corresponde a una familia extensa (hermanos, primos y compadres de distintas generaciones). La estructura de la familia wixaritari ha sufrido cambios considerables en la forma de correlacionarse con un asentamiento en específico. Por un lado, no se manifiestan límites claros y formales entre los individuos que son considerados miembros de una familia en específico, por lo que la distinción que aquí propongo entre familia nuclear y extensa es más en un sentido analítico, para enfatizar un círculo íntimo que suele estar correlacionado de forma más estrecha con el ámbito doméstico en sí, que el círculo más amplio de familiares con los que no se suele convivir con la misma intensidad y frecuencia. En las pequeñas rancherías aisladas de los principales núcleos poblacionales, la familia extensa tiene un correlato claro con alguna ranchería en específico; mientras en los núcleos poblacionales más amplios, la familia extensa se corelaciona con agrupamientos de viviendas contiguas, que en sí parecen ir definiendo lo que en otras poblaciones de mesoamérica se conciben como barrios. En estos ámbitos se suceden las transiciones más aceleradas, por lo mismo la familia extensa, quizás por la misma influencia de la sociedad mestiza, tiene preeminencia relativa con respecto a las zonas más aisladas, donde una ranchería y un espacio de territorio le corresponden a una familia extensa o clan. En las zonas más pobladas, estas manzanas o pequeños barrios cuentan con un patio ceremonial donde realizan los numerosos ritos que cada familia extensa debe celebrar durante el año y en los que el fuego ocupa un lugar especial.

Es relevante señalar que el asentamiento de Bancos de San Hipólito consta de básicamente dos zonas: una de urbanización incipiente, ordenada según los criterios ortogonales de origen colonial y que se encuentra sobre el banco principal del poblado; otra, que es la zona de laderas, donde las rancherías o kiete han mantenido una distribución menos concentrada y una forma tradicional. O sea, las kiete de la zona urbanizada tienen forma cuadrangular, mientras las de las laderas adoptan una forma semi-circular. Los materiales de todas las casas son los mismos: adobe, combinado con 
ladrillo cocido de arcilla y castillos metálicos. Sólo los adoratorios suelen ser construidos con adobe y techo de zacate o pasto y madera.

Los wixaritari ponen la mano de obra y el diseño de las casas. Por lo general cuentan con la asesoría de algún maestro de albañil, que haya tenido experiencia en el campo de la construcción en zonas urbanas. Casi siempre hay uno en cada pueblo. El trabajo es por medio del sistema de cooperación bilateral entre familiares o amistades con lazos de compadrazgo ${ }^{4}$. En este caso la ayuda no se cobra en efectivo, sino que constituye una inversión en espera de reciprocidad. Si " $x$ " ayudó a " $y$ " en la construcción de su casa, entonces " $x$ " espera que " $y$ " le auxilie en un futuro próximo a tumbar monte para preparar un cohamil, o algo que se valore equivalente, según criterios difusos, que no pretenden estar totalmente cuantificados, como lo sería un idealista sistema mercantilista de trabajo. Este sistema de reciprocidad constituye un mecanismo que teje una gran red de relaciones, las cuales al mismo tiempo que afianzan los lazos sociales relacionados con un xiriki, vinculan a sus agentes con otros de su misma étnia en distintos xirikite y tukite; ${ }^{5}$ e incluso esto se recrea con pueblos indígenas vecinos, bajo coyunturas especiales. Este capital social wixarika no se limita al intercambio de trabajo, pues también es sumamente relevante el intercambio de capitales culturales objetivados (Bourdieu, 2000: 144-146), como el alimento que se comparte según una serie de normas jerarquizadas entre los agentes grupales que concurren a las ceremonias y fiestas del Costumbre y del Estado.

Carecen de servicio ordinario de luz, pues, por lo menos hasta 2003, la Comisión Federal de Electricidad (CFE) no había llegado aún a estos lugares. Para iluminar de noche el interior de las viviendas, utilizan focos de neón, alimentados por energía solar almacenada en baterías de automóvil. Este tipo de iluminación la han empleado desde hace unos diez años y la usan por breves lapsos de tiempo, entre una o dos horas diarias. La complementan los palos de ocote (Pinus Montezumae), las velas y las veladoras de cera o de parafina, y las lámparas de petróleo. Las placas solares las

\footnotetext{
${ }^{4}$ Los lazos afectivos entre wixaritari casi siempre se formalizan con el ritual del compadrazgo, aunque no todos los compadrazgos se fundamentan en el afecto, o sólo en el mismo, sino que también responden a intereses fríamente calculados.

${ }^{5}$ Xiriki se refiere a un pequño adoratorio que corresponde a un kie o pequeña ranchería (kiete en plural); Tuki es un centro ceremonial, al cual se adscriben distintos xirikite (plural de xiriki; Tukite es plural de Tuki).
} 
reciben como cumplimiento de promesas de campañas políticas, o por medio de programas federales de corte asistencialista como Progresa. Debido a la pobre infraestructura de tubería, y a la escasez del agua ${ }^{6}$, la ropa la lavan a mano las mujeres a orillas de las afluentes naturales, por las cuales, durante verano, fluyen generosas dosis del líquido, pero en tiempos de secas éste apenas escurre superficialmente por algunos riachuelos. La mayoría de las veces tienen que caminar con la ropa por senderos en empinadas barranquillas. Algunas casas suelen surtirse del líquido por medio de mangueras plásticas conectadas a contenedores de agua alimentados por los flujos subterráneos de las vertientes. Pero la corriente de agua por este medio está lejos de ser permanente, ya que las mangueras se rompen con cierta facilidad, debido a la acción erosiva del clima: sol, viento y agua. También la capacidad del contenedor es insuficiente, por lo que sólo alcanza a repartir agua durante unas dos horas en el atardecer.

\section{Algunos antecedentes cercanos}

Antes de 1967 tan sólo vivían dos familias wixaritari en el lugar donde actualmente se encuentra Bancos de San Hipólito. Aquí me refiero al conjunto de bancos y laderas de aproximadamente un kilómetro cuadrado donde ahora se localiza dicho anexo. Con esto no quiero decir que no hayan existido emplazamientos wixaritari dentro del perímetro de 10,720 hectáreas que actualmente reivindican como de exclusividad wixarika en el conflicto agrario que los involucra. Pequeños grupos de familias en factual estado semi-nómada deambulaban por toda la parte periférica norte del perímetro señalado por un documento virreinal ${ }^{7}$. Del mismo modo, aunque sus asentamientos seguían un patrón estacional de acuerdo a las épocas de lluvia y de

\footnotetext{
${ }^{6}$ Los recursos hídricos son escasos. El arroyo Gualajara, en su camino tierra abajo, pasa junto a Bancos, para después ser tributario del río Cora o río Jesús María. Este angosto afluente es perenne, sin embargo durante la etapa más crítica de la época de secas, tan sólo fluye una pequeña corriente de agua que, aseguran los lugareños, nunca se seca.

${ }^{7}$ Los wixaritari han presentado en sus diversos litigios agrarios un título del siglo XVIII con el cual justifican sus reivindicaciones territoriales actuales. Más información al respecto se encuentra en Liffman, 2002.
} 
sequía ${ }^{8}$, las convulsiones sociales de las revoluciones y su posterior inestabilidad les impedía el asentarse en puntos fijos por los cuales rotar estacionalmente. Su herencia cultural directa no es semi-nómada chichimeca, sino agrícola mesoamericana, pero las condiciones bélicas revolucionarias forzaban la nomadización de los indígenas locales. Con la pacificación relativa de la zona y con la implementación de los planes de concentración poblacional indigenistas, ahora no hay familias en estado semi-nómada. La mayoría actualmente tiende a ser sedentario, pero siguen practicando peregrinaciones sagradas y migraciones temporales en busca de trabajo a diferentes puntos de las zonas occidente, centro y norte del país.

En 1968, con los programas indigenistas del gobierno federal se puso en marcha un programa de concentración poblacional instalando una escuela-albergue y un centro de salud. Estos servicios constituyeron la base para atraer a un gran número de wixaritari que habitaban los alrededores de forma dispersa y que practicaban un modo de vida semi-nómada provisional. La transformación teledirigida del patrón de asentamiento indígena, es una de las acciones fundamentales señaladas en el recetario antropológico integracionista que Aguirre Beltrán legó al Instituto Nacional Indigenista de México (INI). Se trabajaba bajo la premisa básica de que a mayor concentración poblacional, mayor era la posibilidad de desarrollar a los grupos indígenas, y, en planos de mayor igualdad, integrarlos así a la sociedad nacional (Aguirre, 1991; INI, 1971). En su intentona integracionista, los agentes gubernamentales implantaron proyectos de salud (vacunación, desparacitación, nutrición, etcétera) y proyectos de desarrollo agropecuario por medio de la introducción de ganado y semillas. Sin embargo, debido a lo recóndito de esta zona, el plan Huicot desempeñó un papel local más modesto con respecto a otras zonas de Jalisco y Nayarit. La infraestructura que se facilitó fue mínima, y los programas que se implementaron fueron inconstantes por las dificultades de acceso, según me comentó un trabajador mestizo de la actual Comisión para el Desarrollo de los Pueblos Indígenas (CDI, antes INI), en la agencia de San Antonio de Padua, quien ha trabajado en la zona desde 1975.

\footnotetext{
${ }^{8}$ Weigand (1992: 34-44, 54-68) y Torres (2000: 119-150) ofrecen estudios detallados sobre los sistemas agrícolas de otras dos diferentes subregiones wixaritari: San Sebastián y Santa Catarina, respectivamente. 
El papel del Estado Mexicano durante el siglo XIX y la primera mitad del XX fue, o de vigilante a larga distancia de la paz de los indígenas, o de frente armado en las revoluciones, por lo que no implementó un plan sistemático de integración de dichos pueblos sino hasta la segunda mitad del siglo XX. La Iglesia Católica fue más inquisitiva e intentó, siempre con resultados parciales, evangelizar a dichos pueblos, pero las recurrentes convulsiones sociales que azotaron el área le impidió realizar una labor persistente.

Acabándose las dos revoluciones del siglo XX mexicano (la Revolución Mexicana y la Revolución o Guerra Cristera), la Iglesia Católica retomó su labor catequizadora, esta vez alfabetizando y brindando educación básica a algunos indígenas que asistían a sus misiones de distintos puntos de la región. Es así como el Estado Mexicano, en su etapa indigenista que localmente inició en los años sesenta, se valió de los pocos individuos que habían sido alfabetizados para colaborar en el funcionamiento de las primeras escuelas primarias de la zona de Bancos. En este sitio había dos wixaritari que sabían leer y escribir, por lo que colaboraron con la brigada de maestros de zonas urbanas que, mediante los planes indigenistas, echaron a andar una escuela y un centro de salud en 1968. Estos maestros brindaron educación básica y capacitación en aspectos agropecuarios, de salud y jurídicos. En especial la figura de una maestra mestiza de origen urbano exacerbó los ánimos misóginos de los mestizos rancheros, pues según quedó registrado en documentos agrarios y en la memoria de informantes, jugó un papel importante con el asesoramiento jurídico de los wixaritari en la defensa de sus tierras y sus derechos básicos.

Siguiendo las consignas indigenistas, de la misma escuela fueron surgiendo los cuadros del profesorado que habría de ser contratado para multiplicar la capacidad educativa de los proyectos regionales. La evolución propia del magisterio nacional propició que estos profesores viajaran a distintos puntos de la república y adquirieran un considerable capital cultural y político propio del campo de las políticas educativas mexicanas. Se sindicalizaron y politizaron progresivamente. Ese grupo de profesores conforma lo que Dietz (1999) denomina intelligentsia indígena. Ellos, si bien han constituido un sector de su grupo étnico que no ha seguido las pautas tradicionales para obtener los capitales que otorgan prestigio entre los suyos, han equilibrado su 
papel mediante el apoyo de la defensa territorial de su gente, pues dependen de las buenas relaciones con los de su grupo para seguir atrayendo estudiantes a las escuelas rurales.

Es relevante mencionar que en Bancos no existen maestras wixaritari. En la escuela internado del lugar colaboran mujeres wixaritari, pero en el papel de cocinera, barrendera y para lavar las sabanas y cobijas de los dormitorios. Reciben una remuneración económica ínfima por ello. Esta situación también sucede en el centro de salud, donde sólo laboran hombres wixaritari que fueron capacitados de forma básica para atender padecimientos simples y para aplicar vacunas. De estos dos campos, el de salud y el educativo, han salido los principales activistas políticos que han jugado el papel de dirigentes de los movimientos por la recuperación de tierras, así como candidatos políticos a ocupar cargos en gobiernos locales dentro del sistema de gobierno del Estado Mexicano ${ }^{9}$.

Los líderes de las movilizaciones también son todos hombres. A pesar del importante papel que han jugado las mujeres en la movilización, ellas ocupan una posición relativamente subordinada, pues en las asambleas no usan la palabra en una forma equivalente a la de los hombres. Su capacidad de persuasión en las mismas es muy reducida. Sin embargo cooperan férreamente en los campamentos que han organizado en zonas serranas, pues se dedican a preparar los alimentos y a cuidar a los niños.

\section{La división de labores domésticas por género}

Los wixaritari de Bancos dividen sus prácticas domésticas bajo el principio de un esquema general de género y por edades, que sin embargo no presenta fronteras rígidas para algunas labores. El trabajo dentro del hogar es uno de los sectores de actividad que presentan límites más claros. Las mujeres se encargan de criar a los niños y a las niñas la mayor parte del tiempo, desde que nacen hasta su corta edad

${ }^{9}$ En la zona wixaritari comúnmente se practican, de forma un tanto conflictiva, las dos formas de gobierno: la del Estado y la tradicional. Los cargos de los puestos políticos estatales por lo general los ocupan los individuos con mayor nivel educativo, mientras los tradicionales los puede ocupar cualquiera, según sea su prestigio social. 
adolescente. Esto implica el amamantar a las criaturas pequeñas, preparar y servir el alimento, cuidarlos constantemente y educarlos en términos generales. La responsabilidad de proteger, alimentar y velar por la salud de los niños recae principalmente en las madres. Por lo que estas, cuando tienen niños de brazos, deben hacer sus tareas domésticas con los chiquillos a cuestas. Conforme crecen sus hijos, los mayores las auxilian en el cuidado de los menores. Pero aún así, se les exige más a las niñas el cuidar a los hermanitos, que a los niños. De la misma forma, a las mujeres se les enseña a cocinar desde pequeñas. El trabajo de limpieza de las casas y el lavado de los trastes y la ropa, corre a cargo de las mujeres. Aunque algunos hombres de vez en cuando barren algunas zonas de la casa, como el patio. Resulta llamativo el ver que a pesar de que algunas familias poseen bestias de carga (burros y mulas algunos pocos tienen yeguas en no muy buen estado), éstas las destinan para acarrear la leña, la cosecha de granos y para el transporte personal. Pero muy escasamente las utilizan las mujeres para cargar el agua para beber o la ropa recién lavada, que ya húmeda su peso se multiplica. El líquido lo acarrean como en toda el área indígena mesoamericana, en cubos encima de su cabeza, mostrando gran destreza de equilibrio y fuerza. Tienen que extraerlo de pozos muy poco profundos, ubicados a la orilla de los arroyos. La mayoría de los pozos no están bien protegidos para resguardarlos de los animales, por lo que el agua no es de la mejor calidad. Con todo, casi nunca la hierven para beber.

Muy pocas familias tienen refrigerador en casa. En Bancos sólo dos familias pequeñas (compuestas por padre y madre e hijos). Estos aparatos funcionan con gas ordinario, del que se usa para estufas. Por lo general los que poseen refrigerador, lo utilizan para vender bebidas heladas (refresco o soda, y cerveza) y hielos de sabores. Estas familias también poseen estufa de gas, pero casi nunca la utilizan, más que nada por lo costoso del hidrocarburo, aunque también valoran el sabor que sobre los alimentos plasma el fuego de leña. Las parejas que poseen estos aparatos son jóvenes de entre 30 y 40 años de edad, donde el padre de familia tiene un nivel de estudios de primaria. El combustible más apreciado por sus cualidades es el palo de brasil 
(Haematoxylon Brasiletto) ${ }^{10}$. Hombres y mujeres participan en la recolección de leña. Cuando la tarea es muy ardua, debido a las energías que demanda su acopio desde lugares considerablemente distantes, los hombres son los que se encargan de cortarla y transportarla, con el auxilio de bestias. Los límites del piso ecológico donde se encuentra la madera de roble y de palo de brasil, se aleja progresivamente del núcleo poblacional, debido a la tala. Estos factores han incrementado el trabajo implicado en ello.

El encendido del fuego para el hogar, corre a cargo de las mujeres, quienes son las principales expuestas a las emanaciones de humo, que a la larga dañan a las vías respiratorias y a los ojos. Las cocinas se encuentran bajo techo y no tienen buena ventilación, debido a que están bien protegidas contra el paso de animales domésticos y silvestres. Esto hace que el humo se concentre. El trabajo de cocina es arduo y comienza como una hora antes del amanecer, cuando las mujeres se levantan a preparar el maíz para las tortillas. Los hombres casi nunca preparan la comida, al menos que sea birria (matan el chivo, lo desollan ${ }^{11}$, y lo hornean bajo tierra) o carnitas de cerdo en un gran cazo de cobre. Pero esto sólo sucede en algunas fiestas relacionadas con el Estado (finalización de los ciclos escolares) y en celebraciones rituales familiares, tres o cuatro veces al año.

Por lo general comen tres veces al día. Su dieta principal son los derivados de maíz (tortilla, atoles de distintos tipos, tamales y bebidas fermentadas), el chile, el frijol, el nopal y el arroz, más algunas verduras como la calabacita y el chayote. La carne roja, sea de cerdo, de res, o de algún animal silvestre cazado, la consumen entre una a dos veces a la semana, en cantidades moderadas, con excepción de las fiestas, donde ingieren cuantiosas porciones. Ocasionalmente cocinan pescado de agua dulce del río Cora que compran a pescadores itinerantes. La carne de venado, es cada vez más escasa, por lo que casi exclusivamente la comen durante festividades (la almacenan deshidratada, de similar manera a la cecina del occidente de México). La cacería en

\footnotetext{
10 Este vegetal sirve para construcción como travesaño de bóvedas o como poste, pues soporta inclemencias y plagas de termitas; para la hechura de objetos de culto y artesanales, como las varas de mando; también se le atribuyen cualidades curativas para "limpiar" la sangre, los riñones y el hígado. Sin embargo se ha escaseado por la tala desorganizada, obligando a la utilización de leña de otras especies, como el roble (Quercus Rugosa) y el huisache (Acacia Farnesiana) para el fuego.

${ }^{11}$ En general los hombres se encargan de desollar todo tipo de mamífero cazado o sacrificado.
} 
general la practican sólo hombres. Hombres y mujeres recolectan ciruelas, capulines y plátanos en el monte; en los lechos de los arroyos, también hombres y mujeres suelen sembrar algunos papayos y cítricos como el limón real y la naranja agria.

Durante el tiempo que están en el hogar, los hombres, aparte de observar y vigilar, realizan actividades de corta duración, que demandan demasiada fuerza, como persogar o enlazar burros y mulas, o cortar leños. Con excepción de ciertas prácticas específicas como las ceremonias religiosas, la siembra, la cacería y la enseñanza musical y artesanal, la crianza de los niños por parte de los hombres no es intensiva, y su papel es más de vigilante y de reprendedor por mal comportamiento. Sin embargo, durante las ceremonias religiosas o prácticas rituales, el padre, en conjunción con los el marakame y el kawitero ${ }^{12}$, educan a sus hijos varones en consejos prácticos de la vida, por medio de metáforas de origen mítico, transmitidas en cánticos, historias y danzas teatrales. También participan las mujeres en estos ritos, pero asumen papeles diferenciados. La madre y el padre inculcan a sus hijas e hijos pequeños el papel a seguir según las líneas de género y las ceremonias las dirigen los hombres ${ }^{13}$.

Los rituales de carácter mítico propios de El Costumbre, se practican en distintos lugares. Por lo general, los que se rigen por un ciclo más o menos específico y se organizan entre familiares, se ejecutan en los patios de las casas y en los patios compartidos de las manzanas; otros ritos más abarcadores se efectúan en lugares donde se pueden congregar todos los miembros del poblado, como la plaza, patio o kallihuei. En la intimidad del hogar también se realizan ritos que no están estrechamente ligados a un ritmo cíclico y que pueden consistir en curaciones por algún padecimiento físico y / o espiritual; "embrujos" que tienen que ver con relaciones de odio y / o amor; rezos o plegarias dirigidas a deidades específicas en torno a planes $\mathrm{u}$ objetivos específicos, etcétera. Algunos de estos rituales más íntimos pueden estar mediados por la acción o las indicaciones de algún marakame, o pueden ser realizados directamente por los individuos en general.

\footnotetext{
${ }^{12}$ Marakame es la persona investida de conocimiento tradicional sobre historias míticas y poderes de sanación / enfermedad; el kawitero es un narrador de historias míticas. Ambos dirigen ceremonias importantes.

${ }^{13}$ La caza y la siembra, entre otras actividades, casi siempre se realizan en compañía de los hijos, por lo que funcionan como mecanismos de socialización constante.
} 


\section{Actividades musicales y artesanales}

Algunas familias se dedican a la música o a la artesanía. Esta última ha cobrado auge en los últimos treinta años, como actividad no sólo estética y mitológica, sino también mercantil, gracias en gran parte a las sucesivas oleadas de la moda: en 1951 se organizó en Guadalajara una exposición de su artesanía en estambre sobre cera (Weigand, 1992: 193); después, en 1954, durante el periodo del folkclorismo nacionalista, se realizó una exposición de "arte huichol" en el Museo Nacional de Artes Populares (Knab, 1981: 237). Estos eventos contribuyeron bastante a la diseminación nacional de sus productos. Con la onda hippy de 1960 a 1970 se difuminó internacionalmente, sobre todo por la obvia correlación de la inspiración atribuida a la venerada cactácea, con los hábitos psicodélicos de esa generación (Fikes, 1993); ahora, con la nueva era y el movimiento world beat globalizante, continúan reinventándola. Localmente, la artesanía es practicada tanto por hombres, como por mujeres, aunque ellas son las que más producen.

Con esta labor, el espacio doméstico cumple una función más, la de lugar de trabajo o taller artesanal familiar, aunque no todas las familias la ejercen comercialmente. Realizan joyería de chaquira tejida con hilo; cuadros bidimensionales y figuras tridimensionales decoradas con chaquira o con hilo estambre incrustado en cera natural; también se bordan textiles para confeccionar morrales, blusas, pantalones y faldas. La manualidad de chaquira y de estambre sobre cera es realizada por hombres y por mujeres; sin embargo, las figuras de madera que son decoradas con chaquira 0 estambre, son diseñadas y talladas por hombres. La chaquira es trabajada por hombres y por mujeres. Los textiles, aunque también son realizados por miembros de ambos sexos, son las mujeres quienes más los producen. Estos encuentran gran aceptación entre los mestizos, quienes los utilizan para transportar múltiples objetos cuando montan a caballo; o los niños, wixaritari o mestizos, los usan para cargar sus libros cuando van a la escuela.

Sólo las familias que se han capacitado y que han encontrado nichos de mercado costeables, son las que se dedican de lleno a esta actividad, que si bien refleja iconográficamente los mitos de El Costumbre, trasciende las prácticas del mismo y 
responde a valores y flujos de origen externo, de nivel transnacional, por lo que coparticipan en un extenso campo mercantil, donde la interpretación y adjudicación de valores a dichos productos sigue pautas inciertas. Como parte de los valores y creencias nuevos, se estampan imágenes sugerentes como las hojas de marihuana, los "cuernos de chivo" o metralletas Aka 47, palabras en inglés del tipo "I love you", o escudos de clubes deportivos de fútbol. Sin embargo se mantiene la producción de artefactos con fines meramente rituales, como las jícaras sagradas y las varas de mando, que aunque también se venden comercialmente, se seleccionan ejemplares que serán objeto de culto exclusivamente: éstos son objetos que no se les imputa un valor mercantil, sino sagrado, relacionados a un capital social y cultural con pretensiones de exclusividad para el wixarika. Aunque el auge de la artesanía en la localidad apenas comienza a intensificarse, ya conforma una esfera semi-autónoma específica, donde los agentes diseñan estrategias bajo un sentido de competencia, con la finalidad de ocupar una posición ventajosa en el mercado: se esfuerzan por innovar técnicas, formas y texturas nuevas en sus productos, al mismo tiempo que guardan un celo especial sobre sus hallazgos o invenciones, las cuales procuran no compartir con las familias en competencia. El plagio por lo tanto está a la orden del día y no pocas veces es motivo de desavenencias entre las familias de artesanos.

Esta búsqueda por la innovación tiene un gran estímulo en las exigencias de sus intermediarios, quienes requieren de piezas "únicas", como parte de la dinámica de un campo mercantil internacional con preconcepciones sobre lo "auténtico" y cubierto de un halo de exotismo hacia lo "nativo". Esto no quiere decir que hombres y mujeres no se atavíen con los mismos objetos que destinan al mercado, como collares, aretes, pulseras, gargantillas, etcétera, pues los aprecian y los portan con orgullo. Considero que no existen líneas claras y tajantes entre lo propio y lo ajeno en cuanto a la expresividad cultural de estos arte-objetos. Como lo plantea Neurath (2005), para las máscaras seguramente existen diferencias más claras en cuanto a distinción semiótica (esferas comerciales-profanas y tabú-sagradas), para cuyo caso existen máscaras que no entran al mercado y se consideran sagradas, propias de un campo místico, con su dinámica propia. Pero no es así en cuanto a abalorios y a textiles concierne, pues 
resultan los mismos los que se venden y los que ellos portan cotidianamente o en fiestas.

El consumidor que más demanda sus productos es el de Estados Unidos, aunque no es el que mejor paga, según cuentan mis informantes artesanos. Los intermediarios para la exportación son mexicanos de Ensenada, a quienes les venden artesanía al mayoreo y quienes también los han presionado por que se registren ante la Secretaría de Hacienda y Crédito Público de México, con el fin de obtener facturas para comprobación de gastos. En sí esta actividad tiende a incrementarse y sus efectos en la unión o desunión grupal están todavía lejos de vislumbrarse claramente, aunque seguramente agudizará la diferenciación por clases, como ha sucedido en otras poblaciones con mayor tiempo en dicha empresa. Si bien los hombres son los que asumen la función de comerciante en cuanto a contactos mercantiles y a administración del dinero se refiere, las mujeres son las que más mercancías artesanales producen. Ambos colaboran en la venta de artesanía cuando viajan a ciudades con toda la familia. Knab (1981) reporta sobre el caso de Santa Catarina (Tiaupuri) que la "nueva circulación monetaria" ocasionada por la artesanía urbana-rural ocasionó diversas perturbaciones: modificó la forma de residencia al promover una emigración estacional más prolongada de jóvenes hacia la Ciudad de México; tensiones con los patrones de estatus, pues los jóvenes se hicieron de capitales por vías alternativas, desafiando el estatus adquirido por los viejos; cambios en el trabajo "grupal-comunal", pues la prolongada ausencia de jóvenes dificultó la continuación de relaciones de reciprocidad. Por otro lado propició el "renacimiento" o reinvención de los ritos, acentuándolos: la riqueza de los artesanos posibilitó el sacrificio de animales cada vez más grandes con ceremonias mucho más elaboradas, lo que anunciaba un conflicto de estatus con los mayores. En San Lucas de Jalpa se ven efectos similares, pero no están asociados exclusivamente a los efectos de la artesanía, sino a diversos factores propios de otros campos, como el educativo y el de la salud pública.

La actividad mercantil de los wixaritari data de tiempos prehispánicos. Según los estudios de Weigand (1992: 33-105; 2002: 79-93), ellos han mantenido cierta continuidad en el trazado de sus rutas hacia el occidente de Nayarit y hacia el este de San Luis Potosí, caminos a través de los cuales intercambiaban o trocaban objetos 
como el hikuri, plumas, piedras preciosas y utilitarias, etcétera. Para la época anterior a la concentración poblacional de Bancos, los wixaritari de la localidad vendían textiles bordados, sombreros de paja y huaraches a sus vecinos mestizos. Su mercado se amplió con la apertura de caminos y la consiguiente intensificación del comercio nacional y global. Ahora, localmente, quizás algunas familias estén en camino de profesionalizarse, como es el caso de otros lugares de la región, donde incluso algunos wixaritari ya no son considerados meros artesanos, sino artistas con exposiciones itinerantes en algunas sedes del arte mundial, como Ramón Medina y Tutukipa Robles (ambos hombres). Tanto la división local del trabajo entre wixaritari y mestizos, en la que los segundos no se dedican a alguna actividad artesanal por no aceptarlo como propio de su grupo, sino de indígenas (sólo algunos cuantos vecinos trabajan la talabartería para su transacción local), como el apoyo itinerante del Estado para la promoción de la artesanía y el arte indígena (Knab, 1981), contribuyen de manera evidente a propiciar una ventaja local de los wixaritari en el campo artesanal. Pero no encontré casos en los que la mayor aportación femenina a la producción de mercancías les haya redituado a ellas una evidente ventaja de estatus relativa a los hombres, ni en su unidad doméstica, ni en su localidad. En este sub-campo se recrean las líneas de género practicadas cotidianamente en otras esferas sociales.

Los patios, aparte de servir como espacio agropecuario, de almacenamiento, de comedor familiar y de celebración mítico-ritual, también se usan para los ensayos de los conjuntos musicales o mariachis, los cuales sólo utilizan instrumentos de cuerda. El éxito de los tríos, cuartetos y quintetos wixaritari en la región es innegable. Basta asomarse a las "rockolas" de Jesús María para observar la gran cantidad de discos que se ofrecen de grupos de San Andrés Cohamiata, Santa Catarina y San Sebastián. Cabe señalar que la música wixarika también se divide, como la artesanía, entre la de carácter mercantil, que se vende en discos y en vivo durante fiestas de distinta índole, y la música tradicional, entonada con instrumentos especiales durante ceremonias de El Costumbre. En la zona de estudio, prácticamente todos los músicos semiprofesionales son hombres, a diferencia de otras zonas, en las que mujeres han tenido cierto éxito en el ámbito de la música comercial. Los músicos de Bancos tocan en fiestas locales y regionales, tanto wixaritari, como mestizas, amenizando los bailes. En contraste, no 
existe en la comunidad agraria de San Lucas algún conjunto musical de mestizos semiprofesionales o profesionales, aunque algunos sean diestros para la música. Por lo tanto, el papel de los wixaritari como amenizadores de fiestas mestizas es de cajón ${ }^{14}$. Por su trabajo reciben distintas cantidades como remuneración. De entrada les pagan unos 100 pesos por músico, pero si la fiesta se pone bien y se prolonga por horas, pueden ganar hasta 300 o 500 pesos (en 2004). En cuanto a división de trabajo y ventajas comparativas locales sobre el campo de la música, se repite el esquema del campo artesanal, aunque la actividad musical no se ha desarrollado profesionalmente en la localidad.

\section{Transformaciones en las reglas de residencia y de matrimonio}

El espacio doméstico constituye un lugar íntimo donde la socialización es intensiva desde el nacimiento. Una misma casa la suelen ocupar nietos, hijos, padres y abuelos, es decir, cuatro generaciones. También cumple múltiples funciones, pues aparte de constituir el hogar familiar, es huerto, es corral, es taller de artesanía o de música y es centro de reuniones familiares. Su simbolización y funciones se han modificado paulatinamente conforme han ingresado al orden social wixarika nuevos campos como el de la artesanía comercial transnacional o con las modificaciones coyunturales de sus relaciones con el Estado, los partidos políticos y las políticas asistencialistas (campo político). Desde el espacio del hogar los wixaritari desempeñan actividades que les permiten subsistir y reproducirse, ante la imposibilidad de dedicarse exclusivamente a las actividades agropecuarias.

La regla de residencia o destino de vivienda de los recién casados, de haber sido fundamentalmente virilocal, ahora tiende a ser ambilocal: idealmente la esposa del casado, como parte de un intercambio de mujeres con familias emparentadas, se tenía que ir a vivir a casa de sus suegros, donde la suegra sería una nueva madre, que le enseñaría cómo cocinarle al hijo, entre otras cosas. Sin embargo esto ahora se cumple menos, debido a la escasez de espacio que padecen los de Bancos, más las presiones

\footnotetext{
${ }^{14}$ Aquí la estructura de relaciones es inversa al caso de los coras de Santa Teresa, Nayarit, reportado por Coyle (2005), donde el papel de músicos es ocupado por mestizos. 
de la vida actual, en la que los jóvenes cuestionan los valores y las prácticas de sus padres, como la del matrimonio "arreglado" o intercambio de mujeres por vía matrimonial, donde trazaban el destino conyugal de sus hijos e hijas, al señalarles con quiénes se habrían de casar, por medio de alianzas estratégicas de compadrazgo. Ahora se dan algunos casos de hombres que contraen matrimonio y emigran a otros xirikite ubicados en San Andrés Cohamiata o en alguna otra Comunidad Agraria de wixaritari, pues es la única manera en la que a ellos se les abren más posibilidades de obtener tierras para trabajar. En este sentido se practica una residencia principalmente ambilocal.

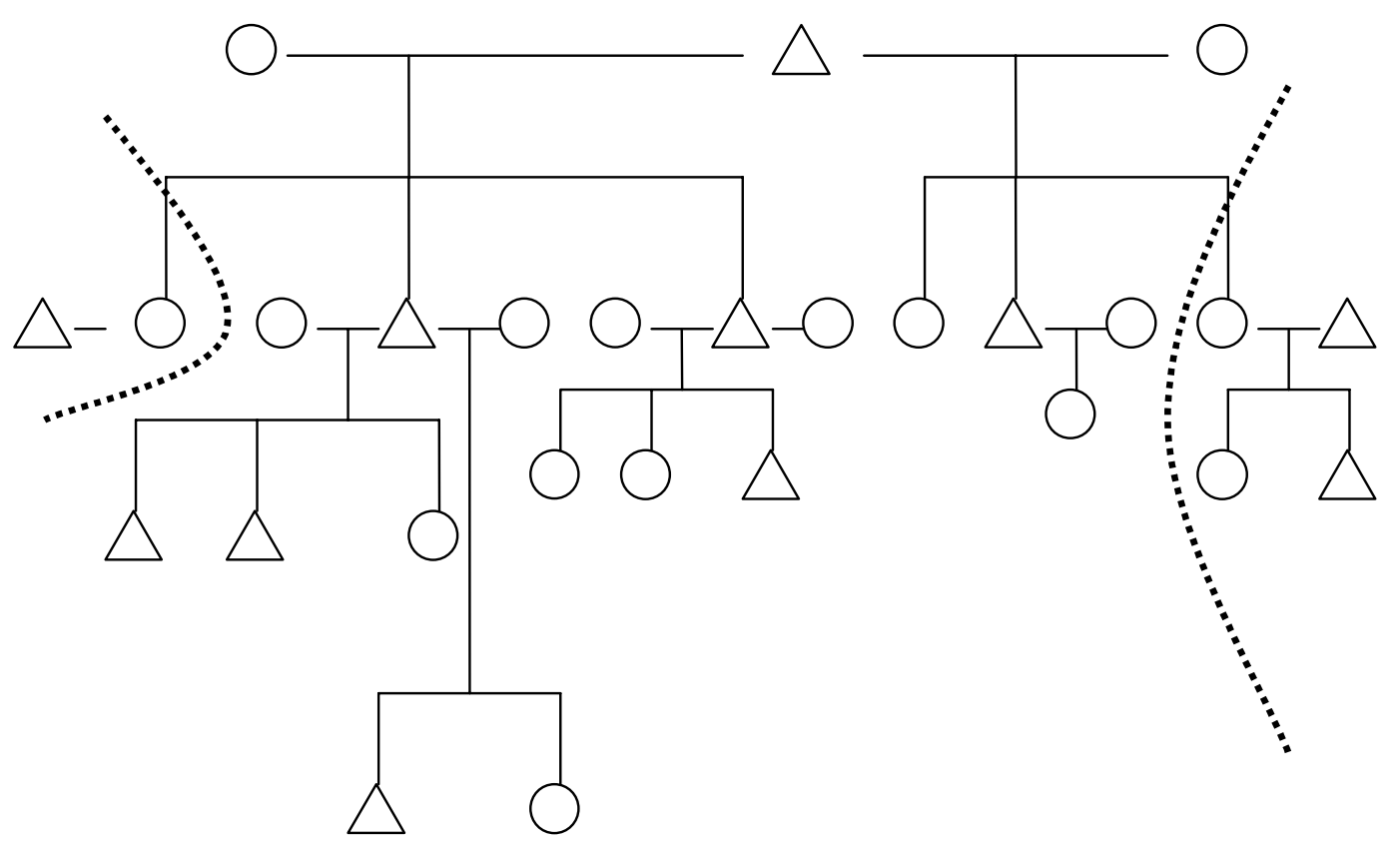

IMAGEN 3. Conformación idealista de una Kie o ranchería, con Modelo de Familia Extensa Polígama, con Regla de Residencia Virilocal y Descendencia Agnática.

Esto también ha reforzado, sobre todo con los de Bancos, los lazos políticos regionales de alianza para la movilización. Claro, no se puede hablar todavía de una transición de un sistema de alianzas matrimoniales basado en un intercambio de mujeres, a uno basado en un intercambio de hombres, o a uno mixto, sino de una adaptación transitoria, que muestra, entre otras cosas, que los principios que rigen a esta étnia no son estáticos, y sus factores organizativos han estado más en función de 
la supervivencia grupal (los límites étnicos), que en función de algún principio inamovible o algún sistema inmutable. La organización social wixarika tiene un pilar importante en la composición de la familia extensa, cuya estructura no ha seguido un patrón específico y estable a lo largo de la historia (Weigand, 1992: 44-54), pues se ha adaptado a circunstancias diversas. Los lazos familiares no implican relación sanguínea en sentido estricto, pues los lazos de compadrazgo, afectivos o de co-residencia pueden ser equivalentes (Weigand, 1992: 49-50). Incluso se puede hablar de lazos de parentesco míticos (Medina, 2002: 209), aunque estos últimos son más relevantes para cuestiones políticas, como la reivindicación territorial de los de Bancos, o identitarias, como se suele manifestar en el contenido de cánticos sobre el origen del pueblo.

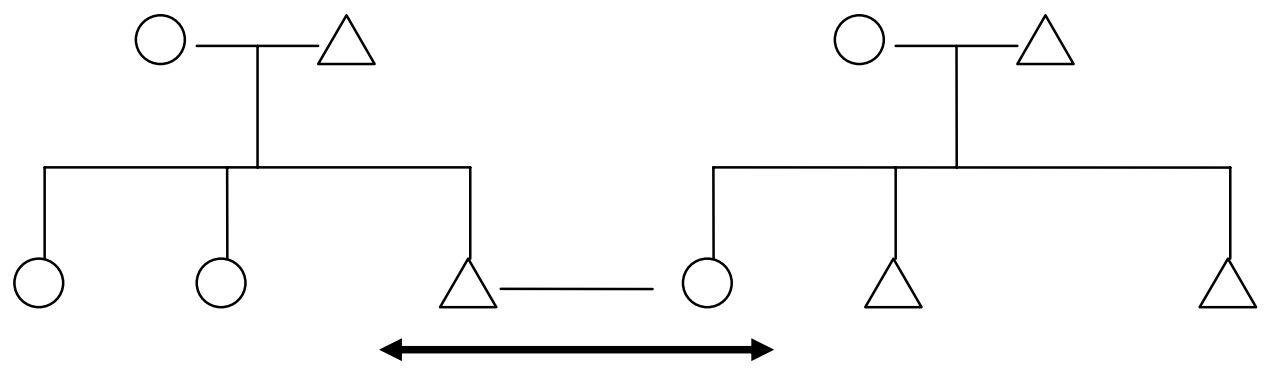

IMAGEN 4. Residencia Ambilocal (Tendencia Actual).

Por lo tanto, para la conformación de una familia extensa y de una familia nuclear, no es condición única el parentesco sanguíneo, como tampoco lo es para la noción de pueblo wixarika. Si bien la noción de "raza" entre wixaritari tiene cierta relevancia, los criterios que la fundamentan son vagos y ni siquiera pretenden ser científicos, aunque no deja de ser un estigma. Los requisitos de la membresía se organizan a diferentes escalas: para ser wixarika (miembro del grupo) los lazos afectivos fundados en un conocimiento personal mutuo no son necesarios, pero se fundan en nociones compartidas intersubjetivamente, sujetas a variaciones situacionales; para ser miembro de un tuki, se requiere cumplir por lo menos con ritos sagrados, donde el conocimiento personal tampoco es condicionante; para ser miembro de un xiriki, aparte del cumplimiento con cargos y ritos, es fundamental el conocimiento 
personal cultivado durante años. Los lazos afectivos tienden a ser más importantes conforme el tamaño del núcleo de población disminuye.

Existe un principio que les ha resultado fundamental para la sobrevivencia grupal en términos locales: la endogamia étnica, donde sólo se toleran matrimonios inter-kiete (inter-rancherías de huicholes), sean hombre-mujer o viceversa, pero no entre wixarika hombre o mujer y un teiwari (no wixarika), sobre todo si es mestizo(a) o extranjero(a). En Bancos, si alguna mujer contrae matrimonio con algún teiwari (alguien no wixarika), es expulsada de su kie. Aunque también es algo inusual que ocurra lo contrario: wixarika hombre con mestiza; incluso wixarika hombre con indígena mujer no wixarika ${ }^{15}$. Con el antecedente de su memoria histórica sobre la incursión de mestizos en San Lucas, su recelo ante la celebración de uniones mixtas es agudo. Las mujeres que se han casado o que cohabitan con mestizos, viven en anexos mestizos, por lo que su descendencia adopta, no sin las dificultades propias del estigma racial, la identidad mestiza. En este sentido, para los matrimonios mixtos, la regla de residencia es la neolocalidad, fuera de la kie o ranchería wixarika: en otro rancho mestizo, de otro grupo indígena, o en alguna zona urbana. Esto es válido para la localidad de Bancos, pues pueden encontrarse variaciones puntuales en otros lugares.

Mestizos e indígenas cuentan que algunos de los pioneros mestizos llegaron a celebrar matrimonios mixtos en San Lucas con el afán de estrechar vínculos con los indígenas coras que en aquél entonces hegemonizaban la comunidad. De esta manera se hacían del derecho de laborar mayores proporciones de tierras $^{16}$. Sus hijos terminaban adoptando la identidad mestiza. Así, paulatinamente en complementariedad con la violencia sistemática y la coerción, desplazaron a los coras, de tal manera que

\footnotetext{
${ }^{15}$ En alguna ocasión conocí en San Andrés Cohamiata (Tateikie) una pareja de hombre wixarika con mujer mestiza. Según información directa de la antropóloga Lorena Bayardo, ella era oriunda del norte de Durango. Se casaron por medio de una alianza de compadrazgo, pues el padre mestizo era compadre del padre del novio. Tanto la apariencia de la mujer (era de tez y cabellos relativamente claros), como sus hábitos y comportamiento, resaltaban en el poblado. Al cabo de dos o tres años terminaron su relación y se divorciaron. Comentaron en broma los wixaritari amigos suyos que a él "no se le quitó lo indio", que cuando visitó a la familia de la muchacha, él seguía con su hábitos que para el mestizo son muy mal vistos, como escupir en el piso interior junto al comedor durante la comida (curiosamente, los wixaritari practican una especial manera de escupir y lo hacen en casi cualquier lugar y a cualquier hora); a ella, durante su estancia entre wixaritari, le achacaban el haberlo engañado con cuanto hombre pudo hacerlo. Por fin, la presión social en ambos grupos pudo más, y terminaron separándose. En Bancos no encontré ningún caso de wixarika hombre con mestiza.

${ }^{16}$ Casos similares reporta Cochet (1991) con los mestizos y nahuas de la costa de Michoacán.
} 
ahora, el único representante cora de la Comunidad Agraria, es una mujer que le calculan algunos cien años, pero que es sorda, casi invidente, y se mueve con suma dificultad. Paradójicamente es la madre de un trío de mestizos que han aterrorizado a wixaritari y a otros mestizos por medio de sus prácticas caciquiles. De hecho uno de ellos se encuentra prófugo en EU porque asesinó a sangre fría, durante la celebración de una boda, a tres mestizos de su anexo. Este tipo de antecedentes, fincados en su memoria sobre las relaciones intergrupales, previenen a los wixaritari de conceder tolerancia a ese tipo de uniones dentro del perímetro de lo que consideran el espacio de los kiete $^{17}$. Esta norma es un mecanismo de control social que manifiesta claramente una territorialidad vigente, que funciona como recurso de poder y de cohesión grupal sistemático.

La función de la endogamia para este caso se entiende mejor desde un plano que analice la interacción intergrupal ${ }^{18}$, que desde un plano monográfico, el cual aísla a la comunidad en términos conceptuales, haciendo aparecer la endogamia como un principio dogmático. En su realidad de minoría étnica se han visto presionados a adoptar mecanismos de supervivencia y reproducción grupal. Estos se han construido en un proceso caracterizado por agudas tensiones ocasionadas por relaciones de poder y de afecto intergrupales e intragrupales. El principio endogámico les ha impuesto un proceso en el cambio de reglas de matrimonio, disminuyendo el número de prohibiciones para ampliar el espectro de enlaces intragrupales inter-rancherías. Sin embargo pervive, en un plano mitológico y a nivel de "pueblo" o comunidad imaginada (Anderson, 1997; Wogan, 2001), la idea de descendencia agnática. No obstante dicha tendencia, los individuos actuales wixaritari se reconocen comúnmente como descendientes cognáticos. Esto es, en el momento de las ceremonias referentes al registro del fuego de un Tuki o centro ceremonial a un Xiriki o ranchería, se enfatiza la ascendencia patrilineal; al mismo tiempo, los individuos se sienten ligados a cuatro Tukite relativos a los del padre, la madre, el suegro y la suegra. Liffman (2005), en referencia a este híbrido sistema de parentesco, alude a una combinación coherente

\footnotetext{
${ }^{17}$ En Guízar (2005) expongo con mayores detalles esta circunstancia histórica.

${ }^{18}$ En sí el fenómeno se debe analizar a diferentes escalas, pues de esa forma se esclarece el papel jugado por múltiples actores, tanto regionales, como del Estado en la conformación de la estructura de relaciones locales.
} 
con su cosmovisión de género, donde la descendencia agnática es enfatizada por el viril registro del fuego, en una escenificación de tipo sinécdoque; mientras el proceso sinuoso que implica flexibilidad en la fijación de normas de matrimonio y reglas de descendencia y residencia, enfatiza un aspecto femenino, representado por la planta de calabaza que crece hacia cualquier dirección. Este fenómeno se puede conceptuar, en alusión a Carsten y Hugh Jones (Liffman, 2005: 72-76), como propio del concepto de Lévi-Strauss sobre les societés a maison (sociedades de casa), las cuales cursan por una transición, enfatizando lazos de parentesco mediante metáforas alusivas a la alimentación o la hoguera, acoplando así sus conceptos y normas a los cambios adaptativos que sufren en pos de la supervivencia étnica.

Sin embargo, como resultado de un largo proceso de resistencia, las mujeres wixaritari han sido relegadas a posiciones ínfimas en la estructura local de relaciones jerárquicas. Es así como en otros mecanismos de resistencia y reproducción, como la poligamia y la tolerancia al incesto, se atisban prerrogativas a favor de hombres. Es importante señalar que entre hombres y mujeres jóvenes aumenta el cuestionamiento hacia la poligamia. Sin embargo, los hombres acusan a las mujeres de promoverla, pues una vez casadas se quejan de que no pueden ellas solas con la carga de trabajo y le piden a su marido que se lleve a vivir a una o dos de sus hermanas para que le ayuden; y, claro está, para que cohabite y procree con ellas. Aparte de que ellos dicen que "cuesta mucho dinero mantener a una sola mujer; ahora imagínese a varias. Eso no está bien, luego no tiene uno para darle de comer a tantos chiquillos".

Pero lo que no se cuestionan es la carga de trabajo que implica la posición que se le asigna a cada género, donde la mujer, esté en una unión monógama o no, debe hacerse cargo de tareas diarias sumamente pesadas. Ellas suelen optar por que sea una hermana suya la que coopere y cohabite en su familia, y no alguna de otra familia, que podría crear competencia y discordia. Los hombres arguyen que las tareas del hogar no son para hombres; y "como no hay fuentes de trabajo en su localidad, por eso es flojo el huichol. Pero si hubiera trabajo, no estaría de flojo".

Los mestizos vecinos les adscriben a los wixaritari el prejuicio de ser pobres por "flojos". Opinan que las mujeres wixaritari trabajan mucho más y ellos se la pasan "emborrachándose" regularmente. Lo que van ganando en sus trabajos esporádicos 
como jornaleros, lo gastan inmediatamente en cerveza que compran comúnmente en tiendas mestizas, por lo que también les imputan el ser sumamente irresponsables, pues pueden tener a sus hijos desnutridos y ellos gastarse todo el dinero en bebidas. Si no fuera por algunas mujeres wixaritari que en verdad trabajan extra para producir textiles y venderlos a mestizos o en mercados de Tepic, sus hijos estarían desahuciados. Consideran los mestizos que son muy pocos los wixaritari que no son "holgazanes" y "borrachos". Por supuesto que es difícil que los mestizos imbuidos en la naturalización de sus prejuicios reconozcan que los wixaritari carecen de igualdad de oportunidades de desarrollo, puesto que los primeros se han organizado para no permitir el acceso de los segundos a los recursos agropecuarios fundamentales de la Comunidad Agraria: la tierra de arado, la tierra de agostadero y el recurso forestal. Curiosamente opinan que el "gobierno" debería proveerles a los "huicholitos" fuentes de trabajo en donde ocuparlos, tales como fábricas o talleres donde produzcan artículos que no tengan que ver con los recursos de la comunidad.

Con todo, ahora los jóvenes dicen optar por el matrimonio guiado por los sentimientos, y no por lo que los padres dispongan, y de preferencia con una pareja por lo menos casado con una sola. Sobre la fidelidad masculina no se pone mucho énfasis, mas para la femenina sí, aunque a las mujeres no se les suele exigir ser vírgenes para el matrimonio ${ }^{19}$. Este aspecto sobre la sexualidad lo realzan como una distinción respecto a los mestizos, cuyos hombres sí les exigen dicho requisito a sus futuras esposas, pues cuando "ven que la mujer ya anduvo con otros hombres, luego ya no la quieren. Aquí entre nosotros no es así. Las muchachitas desde chiquillas andan con uno y con otro, hasta que encuentran alguien con quien casarse", comentan los informantes jóvenes wixarika. Usualmente se suelen casar o unir en pareja (cohabitar sin trámites legales estatales o sin rituales de matrimonio propios del grupo étnico) a una edad que oscila entre los catorce y los diecisiete años, por lo que la noción de

\footnotetext{
19 Algunas muchachas que han emigrado a zonas urbanas adoptan costumbres diferentes, que se reflejan en su modo de vestir, pues comienzan a usar faldas cortas, con medias y zapatillas de tacón. Por lo general estas mujeres ya no vuelven a radicar en su poblado de origen y terminan procreando familia en otras regiones, pero realizan visitas esporádicas para saludar a la familia. Algunas parejas de jóvenes wixaritari, mientras deambulan en Tepic, caminan mano a mano, uno al lado del otro; pero cuando llegan a su poblado, suelen adoptar otra actitud, y el hombre pasa a ocupar el lugar de adelante, mientras la mujer camina a sus espaldas, como tradicionalmente se hace.
} 
adolescencia es casi nula entre ellos, ya que se ven en la impronta de vivir en pareja y criar niños desde temprana edad.

Esta circunstancia se agudiza con las disyuntivas que se han presentado entre generaciones viejas y nuevas: los jóvenes muestran un rechazo creciente hacia el matrimonio arreglado, pero no suelen tomar medidas estrictas de control natal, por lo que son muy pocas las mujeres mayores de veinte años que no han sido madres. Esto, para los mayores, les ha acarreado serios problemas, pues las parejas jóvenes sin casarse son muy inestables y se separan con gran frecuencia. Las jovencitas, que no se hacen el ánimo de quedarse como madres solteras, buscan una nueva pareja, quien por lo general no acepta al o a los hijos que haya tenido su mujer con anteriores parejas. Como reacción, la mujer deja a su(s) hijo(s) con sus padres (abuelos de los niños), quienes se encargan de cuidarlos. Por ello los viejos opinan que era mejor el matrimonio arreglado, porque había más control: "Ahora, aunque se casen con quien ellos quieren, de todos modos no sirve. Se la pasan peleando igual". Los jóvenes aducen que cuando menos esa fue su decisión, y no una impuesta por los mayores. $O$ sea, una opción por el libre albedrío en oposición a la tradición, pero que contrae conflictos sociales nuevos, sobre todo porque se está sucediendo una transición incierta entre una forma de organización a otra. Esta opción por el libre albedrío ocurre en una coyuntura donde confluyen diferentes aspectos de consideración:

a) La tierra es escasa y de bajo valor relativo, por lo que la forma de capital social de los matrimonios estratégicamente concebidos para forjar una alianza en función a la conservación del acceso a determinado espacio de tierra ya no tienen el peso económico que pudieran tener en otras circunstancias de mayor lozanía. Weigand (1992: 144) ya mencionaba una correlación entre clase y cantidad de ganado poseída, donde entre los pobres wixaritari el matrimonio arreglado era mucho menos común que entre los ricos, más preocupados éstos por mantener un patrimonio familiar.

b) Las relaciones de reciprocidad entre las familias quizás ya no sean tan significativas para algunos jóvenes, sobre todo los que han logrado estudiar hasta el bachillerato o licenciatura, pues ellos ahora pueden buscar nuevas alternativas de ingreso económico en esferas sociales diferentes, que suplan o devalúen la ayuda que le puede prestar el capital social de las alianzas interfamiliares y del trabajo agrícola mismo. Incluso los 
jóvenes han mantenido relaciones tensas con los viejos en cuanto a la normatividad que debe regir para obtener los cargos del xiriki, ya que los de menor edad han complementado la adquisición del capital social y cultural que antes se basaba en el cumplimiento de múltiples cargos, faenas, labor agropecuaria y de cacería y pesca, con el capital político y educativo que han adquirido por su ingreso a la escuela y su contacto con múltiples dependencias estatales y grupos políticos de diversa índole.

c) La influencia no sólo de sus vecinos mestizos, sino de la enseñanza oficial, donde se hace énfasis en diversos valores que son opuestos y hasta contradictorios con la tradición, por lo que se propicia una tensión entre diferentes conceptos del valor del capital cultural y social.

d) El doble juego que se ha hecho del derecho por algunos agentes de su grupo: supe del caso en los que una suegra demandó a su yerno por ser polígamo. El inculpado, aparte de estar en unión polígama con dos hermanas, procreó con una de sus hijas, por lo que fue demandado por su suegra, con quien no mantenía buenas relaciones.

Los casos de incesto parecen ser tan comunes como los de cualquier otra sociedad (Meigs y Barlow, 2002; Flores, et al, 1998: 554), con la impronta de que por lo general han sido tolerados por wixaritari, lo cual las hace más evidentes. Esto es, no le anteponen las máscaras que otras culturas procuran colocar, como la de sus vecinos mestizos. Opino que esta tolerancia es un mecanismo de control social, cuasiparalelo a la tolerancia a la poligamia, pues significa ésta una manera de amparar a los hijos que los hombres puedan tener con diversas mujeres o con sus propias hijas. Una mujer que es engañada por su marido, puede quejarse ante las autoridades wixaritari. Éstos castigaran a su marido encerrándolo algunas horas en el $\operatorname{cepo}^{20}$ y condicionándolo a dos cosas: o se casa también con su amante, o la deja y nomás anda con su esposa. Si el hombre acepta casarse con su amante, implícitamente se compromete a cumplir con la alimentación de los hijos que haya procreado con su(s) anterior(es) esposa(s), y con la de los que procree con su nueva mujer. En caso de no hacerlo, las mujeres tiene cierto derecho de pedir la intervención de autoridades para que presionen al marido a

\footnotetext{
${ }^{20} \mathrm{El}$ cepo se refiere al instrumento compuesto por dos maderos gruesos, que al unirse dejan entre los dos algunos huecos por donde se sujetan los píes, las manos o el cuello de los reos. En los poblados wixaritari existen cepos que fueron legados por los jesuitas y franciscanos de la colonia y de la etapa independentista. A los sometidos se les exhibe públicamente desde el interior de una pequeña prisión durante cierta cantidad de horas, dependiendo de la gravedad de su falta.
} 
cumplir con la alimentación de los hijos, o en dado caso, optan por abandonar al marido, con el antecedente de que no cumplió con su compromiso, hecho que servirá de aval en caso de que el marido y / o las autoridades pretendan coercionarla por tal decisión.

Pero tampoco se tolera el incesto con un hijo de parte de una madre, como no se tolera la poliandromia. En este sentido, de entrada existe un juicio no igualitario en sentido de género sobre una práctica que puede ser ejercida potencialmente por hombres y mujeres, por lo que se encubre una prerrogativa masculina al respecto. Aquí entra de forma directa el debate que discuten Meigs y Barlow (2002) sobre el incesto padre-hija como un acto de violencia en sí, o como un acto que se ha prohibido no tanto por la violencia que pueda implicar, sino por su función social como un seguro de intercambio de parentesco y reproducción de grupo, siguiendo la propuesta de LéviStrauss. En este trabajo se asume una postura que devela la violencia de dicho acto. El diálogo en cuestiones de derecho indígena se ha estancado en México a lo largo de todo el sexenio foxista, por lo que el espacio intercultural que demandan este tipo de tópicos está lejos de concretarse en acciones ordenadas y constantes que se encaminen a sensibilizar a los sectores del poder legislativo y judicial del Estado.

Aparte de los conflictos y polémicas que estos sucesos han desatado entre wixaritari, la sugestión que esto puede provocar en la psique de hombres y mujeres, que interactúan bajo una esfera del derecho sin límites claros, donde las fuerzas del Estado pueden transgredir a las de la pujante autonomía, puede ocasionar conflictos y transformaciones mayores, sobre todo tomando en cuenta que fueron miembros femeninos oprimidos de su grupo quienes apelaron a la ley estatal para que interviniera y retara a la tradición local, como lo ha comentado Sierra para otros casos (1997: 137). A lo largo de las innumerables situaciones de adversidad por las que ha pasado este pueblo, las improntas por la supervivencia étnica y biológica han construido instituciones que ahora, con los acelerados cambios de los influjos de la modernidad y con la moralidad cristiana a cuestas, pueden ser severamente cuestionadas por posturas carentes de fundamentos que hayan sido emanados o generados por una acción comunicativa intercultural. Esto puede ser todo un dilema para el debate del respeto legalista por los usos y costumbres, sobre todo si siguen prevaleciendo en el 
panorama las concepciones estáticas sobre la organización de los pueblos indígenas que agentes gubernamentales, algunos académicos, ciertos activistas no indígenas y algunos indígenas mismos pregonan como un hecho.

El trabajo etnográfico, por lo tanto, se puede emplear como herramienta para el estudio a detalle de casos singulares, cuyos resultados pueden aplicarse como una guía inicial para el diseño de talleres interculturales, así como data que incite a la reflexión sobre conjeturas o dilemas jurídicos. Sin embargo, considero que difícilmente se pueden usar como testimonios definitivos sobre las problemáticas que plantea, pues una decisión que involucre acciones concretas del Estado ante los pueblos indígenas, tales como la fijación en papel de leyes constitucionales, deberá hacerse mediante la participación efectiva de los agentes indígenas, respetando su punto de vista sobre los temas a ser tratados. Distintas cuestiones que se han abordado aquí han sido someramente tratados en la etnografía sobre wixaritari, debido quizás a la fuerte carga de idealización que ha nublado a gran parte de la labor antropológica que se ha realizado sobre los mismos. Temas como el incesto, comúnmente han sido omitidos. Personalmente me encontré con dicha temática debido a que los escenarios que observé con mayor detenimiento durante mi labor etnográfica fueron los de la interacción intergrupal - siguiendo la tradición consolidada por Fredrik Barth de analizar los espacios de frontera. En estos lugares es donde fluyen cotidianamente los mensajes referentes a los estigmas y prejuicios intergrupales. El estigma por parte de mestizos rancheros de calificar a los wixaritari como "degenerados" por su tolerancia hacia el incesto y la poligamia, me motivó a indagar sobre los posibles sustentos del primer estigma.

Evidentemente constaté algunos casos de incesto, así como cierta tolerancia hacia los mismos, lo cual no significa una abierta aceptación, ni una práctica generalizada. Son casos aislados, en realidad. Claro, que también supe de algunos casos entre mestizos, encubiertos por un aura de cristianismo de doble moral, cuyo grupo si bien no lo tolera discursivamente (ni jurídicamente), suele omitir su denuncia abierta por motivos circunstanciales a relaciones de poder relativas. Lo mismo es válido para la poligamia, la cual practican en gran medida de forma "secuencial", o sea, mediante uniones extra-conyugales, de las cuales no pocas veces procrean nuevas 
familias, tanto en su localidad, como en el extranjero (Estados Unidos de América). De esta forma se tiene una relación de género en torno a la práctica matrimonio con tintes intergrupales, donde la desigualdad, tanto en un grupo como en otro, se manifiesta en la mayor aceptación de la poligamia de hecho o secuencial, que en la aceptación social de su contraparte que podría ser la poliandromia, de hecho o secuencial.

Entre wixaritari se acepta la poligamia, pues un hombre puede cohabitar con dos, tres, cuatro o hasta cinco mujeres; y se legitima mediante ritos institucionalizados en el orden social consuetudinario, aunque las mujeres, y la mayoría de los jóvenes hoy en día ya no apoyen dicha práctica. En cambio, entre mestizos, constaté una naturalización o interiorización de la práctica polígama secuencial de los hombres, que incluso pueden ser de hecho polígamos, con más de una familia a la cual mantienen de forma siempre relativa. El discurso entre ellos manifiesta tensiones entre lo ilegal, lo ilegítimo y lo socialmente aceptado, aunque de forma solapada, y justificada por un machismo siempre vigente.

De esta manera me resultó más difícil entablar un diálogo sobre dichos casos entre mestizos, donde el tema de incesto es tabú y donde la poligamia se concibe más en términos de infidelidad, que con los wixaritari, donde se puede hablar con mayor naturalidad de dicho fenómeno. Sin embargo es un tema que requiere de mayor estudio, para profundizar de manera óptima sobre sus causas y el sentido del mismo: si es un acto deliberado de violencia hacia la mujer, y si existe la voluntad de las mismas por establecer nuevas normas que lo hagan punible, aun dentro de su sistema oral de resolución de conflictos. La inconformidad de las mujeres y de los jóvenes no conduce linealmente a la negación de su herencia cultural, sino a una reconceptualización integral de la misma. Aquí entra un aspecto importante del derecho, sobre todo lo concerniente a la formalización legalista de normas. En principio, lo plausible sería conducir un cambio normativo no en el sentido de trasponer un sistema formalista jurídico de tradición occidental, sobre el sistema oral y efímeramente formalizado de los wixaritari. Hay que reconocer que si bien la poligamia es una institución legítima entre ellos, eso no significa que esté formalizada en un esquema rígido y lógico-formal, bajo principios filosóficos de origen greco-latino. 
En este sentido, el objetivo del trabajo como el presente, es el de sensibilizar sobre los retos que plantea el abordar, desde un punto de vista jurídico y de género, las relaciones de poder intra-grupales en su vinculación con el tema del respeto de los usos y costumbres indígenas. Las visiones que abogan por el respeto a los mismos, siempre y cuando no afecten los derechos individuales de las personas, entran en tensión con las posturas que abogan por la defensa de los derechos de los grupos. Sobre este punto, considero que la noción de reorganización étnica no es incompatible con la idea de defensa del derecho de los pueblos indígenas a la supervivencia como grupo, pues la idea de proceso o cambio puede ser consecuente con la noción de mantenimiento de los límites étnicos. Por ello resulta relevante el tratar de comprender, desde un punto de vista relacional, los mecanismos que fijan a un nivel intragrupal las normas que regulan a las relaciones de género y las prácticas sexuales a través de las cuales se manifiestan.

\section{Síntesis y delineación de tendencias}

Bajo la coyuntura representada por la implementación de los planes desarrollistas del INI, cuya consolidación fundamental fue el plan Huicot, se aceleró un proceso de reorganización étnica para los wixaritari de la zona disputada que consistió básicamente en:

a) Cambio en la densidad demográfica o en el tipo de asentamiento: de disperso, a concentrado ${ }^{21}$.

b) Cambios demográficos que en sí han constituido una verdadera estrategia natalista (Schlee, 2004: 138-143): en la década de 1960 eran alrededor de 300 wixaritari por 500

\footnotetext{
${ }^{21}$ En otras zonas del kiekari o territorio wixarika, el proyecto de concentración poblacional se ha quedado a medias, no sólo en sus aspectos desarrollistas, sino en su impronta fundamental de re- ordenación territorial, pues la mayoría de los pobladores de las gubernancias, anexos, o tukite y xirikite de las comunidades agrarias donde se implementaron los planes, suelen practicar, si no un tipo de asentamiento semi-nómada, tampoco una vida declaradamente sedentaria, pues poseen en su mayoría ranchos o xirikite familiares a los cuales visitan por temporadas (algo "lejanamente" similar a los ranchos de aguas de los mestizos). Si tomamos en cuenta que también emigran estacionalmente en busca de trabajo asalariado y / o espacios de mercado para su artesanía, es muy poco el tiempo que habitan factualmente en su núcleo poblacional principal; en San Lucas de Jalpa esto no es así debido al espacio tan estrecho del que disponen.
} 
mestizos; ahora son alrededor de 910 por 384, respectivamente. Esta estrategia, aunada a la de la exclusión-inclusión intergrupal, enfatiza los hechos de las acciones en pro de la tolerancia de ciertas prácticas: a los hijos de relaciones incestuosas y a los de madres jóvenes no se les ha excluido del grupo; antes bien se han concertado mecanismos para su cuidado básico: a los padres incestuosos no se les priva de su libertad, pues deben criar a sus hijos; a los hijos de las madres solteras se les da cobijo con parientes en caso que la madre los abandone. En la práctica las cosas no suelen funcionar de maravilla, pues los problemas afectivos y de desnutrición suelen ser más severos en estos casos, pero la tendencia ha sido buscar la atención mínima para mantener vivos y unidos a los miembros del grupo.

c) Cambios en las reglas de residencia: de haber sido preferentemente patrilocal, ahora tiende a ser ambilocal. Si bien se amplió el ámbito de endogamia que estaba circunscrito a un kie particular, el límite étnico se mantiene férreo en una endogamia intragrupal (respecto al grupo étnico wixarika), lo cual permite diversificar las opciones de supervivencia étnica, y amplía las alianzas políticas.

d) Tendencia al cambio de tipos de matrimonio, en la forma de ser ideado y de las prácticas sexuales que subyacen al mismo: de ser arreglado, a libre albedrío; de ser polígamo, a monógamo; de tolerarse el incesto padre-hija, a cero tolerancia. Esta transición se tornará más compleja conforme se intensifiquen los flujos culturales y económicos, ocasionando tensiones con los aspectos señalados en "b).".

e) Creación de nuevos campos y subcampos sociales: el sub-campo mercantil (y artístico) de la artesanía se ha expandido con una consiguiente especialización de los artesanos, mediante un traslapamiento de esferas mercantiles y artísticas; el sub-campo político de la política educativa ha forjado nuevos personajes: los profesores y los alfabetizados. Se propició la consolidación de los campos político y jurídico, pues las políticas agrarias de los planes desarrollistas impulsaron en conjunto con sus demás programas, una concentración de intereses en torno al derecho y la política (Guízar, 2005). Sin embargo, la participación de las mujeres en el campo artesanal no les ha redituado mayores ventajas en cuanto a estatus, mas sí en cuanto a diversificación de opciones de ingreso monetario para subsistencia familiar.

La organización étnica en torno a las relaciones de género se ve alterada de forma evidente por una compleja y cambiante estructura de relaciones interétnicas, que 
a su vez es permeada transversalmente por una conflictiva estructura clasista. La movilización reciente de los de Bancos manifiesta la expresión de una pulsión reactiva hacia un estado hegemónico que han pretendido imponer los mestizos, en el que los wixaritari se habrían de mantener subordinados, con la mujer indígena al fondo de la jerarquía. Esta movilización, en combinación con las acciones jurídicas y políticas del Estado, propiciará una paulatina modificación en las pautas de las relaciones de género en la localidad. Los wixaritari tendrán que idear nuevas formas de interpretar los cambios. No sería la primera vez en que se tendrían que reorganizar exitosamente en función de la supervivencia étnica; esperemos que logren construir relaciones y concepciones sobre lo "nuestro" que propicien una mejor situación física y psicológica de las mujeres wixaritari. La inconformidad femenina se manifiesta en la cotidianidad y por medio del uso del derecho del Estado. En este sentido, muchas de ellas no consienten una idílica división por género del trabajo. Padecen tensiones entre las presiones sociales de sus comunidades, y la violencia estructural de la sociedad racista y clasista que las rodea. La resistencia histórica de ellos ante una adversidad centenaria es loable, así como su capacidad de adaptación a las circunstancias coyunturales. Sin embargo, la adversidad cobra víctimas, y comúnmente son los más débiles, como las mujeres y los niños. Considero que, mediante el afianzamiento de redes de solidaridad, la sociedad mestiza debe contribuir a la consolidación de mesas de diálogo donde se planteen opciones legales de respeto a usos y costumbres que realmente quieran ejercer hombres y mujeres en sus localidades.

\section{Bibliografía}

Aguirre, Gustavo (1991). [1967] Regiones de refugio. El desarrollo de la comunidad y el proceso dominical en mestizoamérica. México DF: Fondo de Cultura Económica / Instituto Nacional Indigenista.

Anderson, Benedict, (1997). Comunidades imaginadas. Reflexiones sobre el origen y la difusión del nacionalismo. México DF: Fondo de Cultura Económica.

Bourdieu, Pierre (1992). Réponses. Pour une anthropologie réflexive (con Loïc J. D. Wacquant). Paris: Seuil. 
Bourdieu, Pierre (2000). Poder, derecho y clases sociales, Bilbao: Editorial Desclée de Brouwer.

Carsten, Janet y Hugh-Johnes, Stephen, Ed. (1995). About the house: Lévi-Strauss and beyound. Cambridge: Cambridge University Press.

Cochet, Hubert (1991). Alambradas en la sierra: un sistema agrario en México. La sierra de Coalcomán. México DF: CEMCA / El Colegio de Michoacán / ORSTOM.

Coyle, Phillip E. (2005). Procesos rituales contradictorios: asumiendo un cargo en Santa Teresa (Nayarit). Relaciones. Estudios de historia y sociedad, XXVI(101): 123-145.

Dietz, Günther (1999). "Desencuentros", "encontronazos" y "reencuentros": movimientos indígenas y organizaciones no-gubernamentales en México, Indiana, 16: 29-50.

Fikes, Jay C. (1993). Carlos Castaneda, academic opportunism and the psychedelic sixties. Victoria, Canada: Millenia Press.

Flores, Renato Z., Mattos, Luiz F. C. y Salzano, Francisco M. (1998). Incest: frequency, predisposing factors, and effects in a brazilian population. Current Anthropology, 39(4): 554-558.

González, Felipe y Vizcarra, Ivonne (2006), Mujeres indígenas en el Estado de México. Toluca, México: El Colegio Mexiquense / Universidad Autónoma del Estado de México.

Guízar, Francisco (2005). La difícil coexistencia. Disputas jurídicas por el territorio entre wixaritari y mestizos de Durango. Tesis doctoral, Centro de Estudios Rurales, El Colegio de Michoacán, Zamora, México.

Hernández, Rosalva A. (2001). Entre el etnocentrismo feminista y el esencialismo étnico. Las mujeres indígenas y sus demandas de género. Debate Feminista, 12(24): 206-230.

Hernández, Rosalva A. (2003). Posmodernismos y feminismos: diálogos, coincidencias y resistencias. Desacatos. Revista de Antropología Social, 13: 107-121.

INI (1971). Acción Indigenista en la Zona Cora-Huichol. México DF: Instituto Nacional Indigenista (INI).

Knab, Tim (1981). Artesanía y urbanización: el caso de los huicholes. América Indígena, XLI(2): 231-243.

Liffman, Paul (2002). Huichol Territoriality: Land, Conflict and Cultural Representation in Western Mexico. Tesis doctoral en antropología, Department of Anthropology, University of Chicago.

Medina, Héctor (2002). Los hombres que caminan con el sol: organización social, ritual y peregrinaciones entre los huicholes del sur de Durango. Tesis de licenciatura en antropología social, Escuela Nacional de Antropología e Historia, México. 
Meigs, Ana y Barlow, Kathleen (2002). Beyond the Taboo: Imagining Incest. American Anthropologist, 104(1): 38-49.

Nagel, Joane y Snipp, Matthew (1993). Ethnic reorganization: american indian social, economic, political and cultural strategies for survival. Ethnic and Racial Studies, 16(2): 203-235.

Neurath, Johannes (2005). Máscaras enmascaradas. Indígenas, mestizos y dioses indígenas mestizos. Relaciones. Estudios de historia y sociedad, XXVI(101): 21-50.

Schlee, Günther (2004). Taking sides and constructing identities: reflections on conflict theory. The Journal of the Royal Anthropological Institute, 10(1): 135-156.

Sierra, María T., (1997). Esencialismo y autonomía: paradojas de las reivindicaciones indígenas. Alteridades, 7(14): 131-143.

Torres, José de Jesús (2000). El hostigamiento a "El Costumbre" huichol: los procesos de hibridación social. Zamora: El Colegio de Michoacán.

Weigand, Phil C. [Beatriz Rojas, ed.] (1992). Ensayos sobre el Gran Nayar: entre Coras, Huicholes y Tepehuanos. México DF: INI / CEMCA / El Colegio de Michoacán.

Wogan, Peter (2001). Imagined Communities reconsidered. Is print-capitalism what we think it is? Anthropological Theory, 1(4): 403-418. 